\title{
Optimization of Biodiesel Production from $60-90 \%$ Initial Free Fatty Acid Raw Materials
}

\author{
Penjit Srinophakun, Kultawat Tepjun, Anusith Thanapimmetha, Maythee Saisriyoot \\ Chemical Engineering, Kasetsart University \\ 50 Ngamwongwan Road, Bangkok, Thailand \\ fengpjs@ku.ac.th; fengjrc@ku.ac.th; fengmts@ku.ac.th
}

\section{Extended Abstract}

This research aimed to find the optimized conditions which gave the lowest final free fatty acid of biodiesel production from $60-90 \%$ initial free fatty acid (FFA) raw material using esterification reaction. Final FFA is crucial for commercial biodiesel quality and it should meet the standard value of less than $0.5 \mathrm{mg} \mathrm{KOH} / \mathrm{g}$. Therefore, this study tried to minimize FFA of the first step biodiesel production using acid catalyst in esterification reaction. The raw materials were prepared by mixing Palm Fatty Acid Distillate (PFAD) and Palm Stearin (PS). The percentage of FFA in PFAD and PS were 90.6 and 0.35 respectively. Box-Behken response surface method was used to design the experiment with three level and three parameters at fixed $60 \%$ and $80 \%$ initial FFA raw materials [1]. Three parameters were $\%$ catalyst, molar ratio of alcohol to free fatty acid and reaction time [2]. Three levels of $\%$ catalyst was $0.5,2.25$ and 4 weight $\%$. While three levels of molar ratio of alcohol to free fatty acid and reaction time were 3:1, 11.5:1 and 20:1, and 30, 135 and 240 minutes. With Minitab program, 27 experiments were designed, and final FFA of each experiment was analysed. The results from running the optimization from Minitab program gave the optimization equation as following.

$$
\begin{gathered}
F F A_{f}=49.1557-7.93779 X_{1}-4.42289 X_{2}-0.20992 X_{3}+0.267694 X_{4}+0.776256 X_{1} X_{1}+0.130034 X_{2} X_{2} \\
+0.000218084 X_{3} X_{3}+0.000179302 X_{4} X_{4}+0.265224 X_{1} X_{2}+0.0186558 X_{1} X_{3} \\
-0.0414454 X_{1} X_{4}+0.00457059 X_{2} X_{3}-0.0132794 X_{2} X_{4}+0.00017198 X_{3} X_{4}
\end{gathered}
$$

For the initial free fatty acid of $80 \%$, the optimum conditions were $2.3 \%$ acid catalyst, $15.3: 1$ molar ratio of alcohol and free fatty acid and 240 minutes reaction time. Then the experiment was performed to valid the equation. It was shown that $3.29 \%$ final free fatty acid was deviated from the simulation results at $80 \%$ initial FFA raw material.

At the end the profiles of time and initial FFA of raw materials, mole ratio of methanol and FFA and initial FFA of raw materials, $\%$ of acid catalyst and initial FFA of raw materials, and the final FFA and initial FFA of raw materials were plotted [3]. These profiles were very useful as a guideline for the optimization conditions of the first step biodiesel production particularly of $60-90 \%$ initial FFA raw materials.

\section{References}

[1] G. E. P. Box and D. W. Behnken, "Some new three level designs for the study of quantitative variable," Technometrices., vol. 2, pp. 455-475, 1960.

[2] M. Charoenchaitrakool and J. Thienmethangkoon, "Statistical optimization for biodiesel production from waste frying oil through two-step catalysed process," J. Fuel Processing Technology, vol. 92, pp. 112-118, 2010.

[3] G. E. P. Box and N. R. Draper, Response Surface, Mixture and Ridge Analyses, 2nd ed. John Wiley and Sons, Inc., Hoboken, New Jersey, 2007. 